\title{
Causes of maternal death at Natalspruit Hospital, Johannesburg, South Africa
}

\author{
B Uzabakiriho, FCOG (SA), MMed (Obstetrics and Gynaecology); S Maswime, FCOG (SA), MMed (Obstetrics and Gynaecology), PhD
}

Wits Obstetrics and Gynaecology Clinical Research Division, Department of Obstetrics and Gynaecology, Faculty of Health Sciences, University of the Witwatersrand, Johannesburg, South Africa

Corresponding author: B Uzabakiriho (buzabakiriho@gmail.com)

Background. Despite increased resources to reduce maternal deaths, South Africa (SA) has an unacceptably high maternal mortality rate (MMR). Objectives. To determine the causes of maternal deaths at Natalspruit Hospital, Johannesburg, SA.

Methods. A 2-year retrospective audit of case records was done All maternal deaths from January 2013 to December 2014 were included. Results. There were 20676 live births and 79 deaths, with a MMR of 382.08/100 000. Forty-four women (56\%) were HIV-positive, $14(21 \%)$ died of obstetric haemorrhage and $12(15 \%)$ had hypertensive disorders of pregnancy. Thirty women (38\%) had not attended an antenatal clinic. More women died between $16 \mathrm{~h} 00$ and $08 \mathrm{~h} 00$ than between $08 \mathrm{~h} 00$ and 16h00. Most women (88\%) had at least one avoidable factor.

Conclusions. Natalspruit Hospital has a high MMR. The majority of deaths were HIV-related. There was a high number of women who were unbooked. Most deaths occurred after normal working hours.

S Afr Med J 2019;109(6):412-414. DOI:10.7196/SAMJ.2019.v109i6.13215

According to the World Health Organization (WHO), 800 women die per day globally owing to pregnancy-related complications. The lifetime risk of a woman dying from a pregnancy-related cause in a low-income country is 25 times higher than in a high-income country. High-income countries have a much lower mortality rate than low-income countries. ${ }^{[1]}$ Since the inception of the National Committee on the Confidential Enquiries into Maternal Deaths in October 1997, maternal mortality has been the main indicator used to measure the quality of care in South Africa (SA). ${ }^{[2]}$ Despite the increase in resources countrywide to prevent maternal mortality, SA nevertheless has a highly unacceptable maternal mortality rate (MMR). The MMR is 127/100 000 in developing countries compared with $16 / 100000$ in developed countries. ${ }^{[3]}$ SA had an institutional MMR (iMMR) of 154/100 000 in the 2011 - 2013 Saving Mothers Report. ${ }^{[4]}$ A review of maternal deaths in SA shows an increasing number of deaths between 1999 and 2010. ${ }^{[2]}$ Ekurhuleni District was among the poorly performing districts in SA.

The aim of the study was to assess the causes of maternal deaths at Natalspruit Hospital, Johannesburg, SA, and to make recommendations to improve the quality of care.

\section{Methods}

Natalspruit Hospital is situated in the Ekurhuleni District in Gauteng Province. Gauteng is the smallest province in SA, but has the highest number of deliveries. At Natalspruit Hospital there is an average of 12000 live births per year. It has a total of 821 beds, and 134 beds in the obstetrics and gynaecology department. It is a regional hospital, with an intensive care unit (ICU) and an obstetric highcare unit. Two district hospitals (Bertha Gxowa and Heidelberg hospitals) refer to Natalspruit Hospital and 5 midwife obstetric units. Natalspruit Hospital refers to Chris Hani Baragwanth Academic Hospital, which has an ICU, a blood bank and laboratory services. The ICU is managed by critical care nurses, and doctors from each department review patients during morning ward rounds, as well as for emergencies.
A retrospective audit was conducted using case records of all the women who died during January 2013 - December 2014. The definition of a maternal death was as follows: a woman who died during pregnancy, labour or up to 42 days after delivery.

Age, nationality, parity, attendance at an antenatal clinic and HIV status were described. The events leading to the time and cause of death were assessed. Time of death, and whether it occurred in the evening or during a weekend, when the department had fewer staff members on duty, was evaluated. Avoidable factors were described according to whether they were patient related, healthcare worker related or institutional.

Data analysis was done with Stata version 12.0 (StataCorp., USA), using descriptive and analytical techniques.

\section{Ethical approval}

Ethical approval was obtained from the University of the Witwatersrand Human Research Ethics Committee (ref. no. M141149). Permission to conduct the study was obtained from the chief executive officer and the head of department of Natalspruit Hospital. The hospital has since moved to another location in the Ekurhuleni District and in 2015 was renamed Thelle Mogoerane Hospital.

\section{Results}

There were 20676 live births and 79 deaths in the 2-year period. The MMR was 382.08/100 000, and the mean age was 29 (standard deviation (SD) 5.47; range 14 - 40) years. All women were of African descent (black females). The majority (91\%) were South African, except for 1 woman from Lesotho, 1 from Madagascar, 3 from Mozambique, 1 from Zimbabwe and 1 from Malawi. The mean parity was $2(1.42 ; 0$ - 5). Forty-seven women (59\%) attended an antenatal clinic, 29 (37\%) did not attend and 3 were unknown. The mean hospital stay was $4.8(5.65 ; 0-35)$ days. The modes of delivery were caesarean section $(n=22 ; 28 \%)$ and normal vaginal delivery $(n=32$; $40 \%) ; 25$ (32\%) were undelivered at time of death. 
Patient characteristics are set out in Table 1. Forty-four women (56\%) were HIV-positive and HIV status was unknown in 17 (21\%). Thirty women $(38 \%)$ had not attended an antenatal clinic. Fourteen women were referred: 5 from midwife obstetric units, 8 from the referring hospitals (Heidelberg and Bertha Gxowa hospitals) and 1 from Chris Hani Baragwanath Academic Hospital, as she had to be admitted to an ICU.

The leading causes of death were HIV-related infections in 44 women (56\%), obstetric haemorrhage in $14(21 \%)$, hypertensive disease in $12(15 \%)$, sepsis in $2(2 \%)$ and medical disorders in $2(2 \%)$. Early pregnancy deaths were due to ectopic pregnancy in 3 women (4\%) and incomplete miscarriage in 2 (2\%) (Fig. 1)

Fifteen women (19\%) were admitted to the ICU before death. There were more deaths during the week $(n=55 ; 69 \%)$ than during a weekend $(n=23 ; 29 \%)$; for only 1 woman was the time of death not recorded. More women died after $16 \mathrm{~h} 00(n=30 / 55$; 55\%) than before $16 \mathrm{~h} 00(n=25 / 55 ; 45 \%)$ from Monday to Friday. Twenty-three women (29\%) died on a Saturday or Sunday. A total of 53 women (67\%) died after working hours. At the time of collecting the data, Natalspruit Hospital had 2 specialists and 10 medical officers. During the day $(08 \mathrm{~h} 00-16 \mathrm{~h} 00)$, most of the doctors are available on site; however, after 16h00, 2 medical officers and an intern are on call - 1 in theatre, while the others cover the labour, antenatal, postnatal and gynaecology wards and gynaecology emergency admissions. Each specialist is on call off-site for 15 days a month for emergencies.

Avoidable factors were described as patient related, healthcare worker related or healthcare system related. Seventy of the deaths $(88 \%)$ had at least 1 avoidable factor. For the majority of women $(\mathrm{n}=46 ; 58 \%)$ there was a patient-related factor, while 42 women $(53 \%)$ sought medical attention late. There were fewer women $(n=23 ; 29 \%)$ in whom an avoidable healthcare system factor played a role. Five women who had to be admitted to an ICU were not admitted because

\begin{tabular}{ll} 
Table 1. Patient characteristics $(\boldsymbol{N = 7 9 )}$ & \\
\hline Characteristics & Frequency, $\boldsymbol{n}(\%)$ \\
\hline HIV-positive & $44(56)$ \\
Unbooked & $30(38)$ \\
Referral & $14(18)$ \\
Intensive care unit admission & $15(19)$ \\
Died after 16h00 & $47(59)$ \\
Died before 16h00 & $32(41)$ \\
Died during the week & $56(71)$ \\
Died during the weekend & $23(29)$ \\
&
\end{tabular}

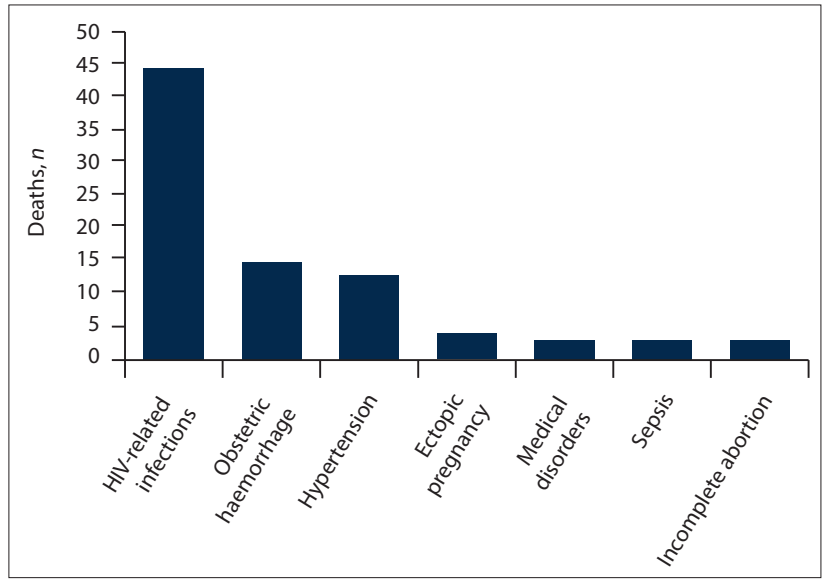

Fig. 1. Causes of maternal deaths. of a shortage of beds. There were also too few blood and dialysis facilities. In 29 women, healthcare worker-related factors played a role, including poor monitoring and failure to make a decision to intubate when a patient required ventilation.

\section{Discussion}

This audit reveals that the MMR at Natalspruit Hospital during the study period was higher than the national iMMR, and also higher than the iMMR of regional hospitals (243.62/100 000) in 2011 2013. ${ }^{[4]}$ Reasons for the high iMMR in Ekurhuleni District have not been explored. The HIV rate for this study was higher than the SA rate. As reflected in Confidential Enquiries into Maternal Deaths of $2011-2013,{ }^{[4]}$ HIV remains a considerable risk factor for women who are pregnant and within 6 weeks after delivery. However, the triennial report demonstrated a decrease in maternal deaths related to HIV. This decline has been attributed to the roll-out programme of antiretroviral drugs. At Natalspruit Hospital, 55.6\% of maternal deaths during the audited period occurred in HIV-positive women. This rate is in keeping with the high HIV infection among women who died as a result of non-pregnancy-related infections, as indicated in the 2011 - 2013 triennial report. ${ }^{[4]}$

Thirty-eight percent of maternal deaths occurred in women who were unbooked, i.e. women who did not seek professional healthcare during their pregnancy. When unbooked patients present in labour, the risk of poor maternal outcome and perinatal morbidity and mortality increases. ${ }^{[5]}$ In another study done in Nigeria, an MMR of $18518 / 100000$ was recorded among unbooked mothers at Jos University Teaching Hospital. ${ }^{[6]}$ Unbooked women know where the health facility is located, and the importance of booking. They choose not to attend antenatal services without an obvious reason. ${ }^{[7]}$

Some of the causes of death mirrored the national causes of death, but there were more deaths early during pregnancy than expected. Four percent of women died as a result of ectopic pregnancy and another $2 \%$ because of miscarriage. According to the SA Confidential Enquiries into Maternal Deaths, ${ }^{[4]} 2.35 \%$ of deaths resulted from ectopic pregnancy in the $2011-2013$ triennium. The percentage has consistently remained $<2 \%$ and has only increased in the last triennium. Death related to ectopic pregnancy is uncommon, even in developed countries. A systematic WHO review of 2006 of the causes of maternal death, described a MMR from ectopic pregnancy of $0.5 \%(0.0-3.3 \%)$ in Africa. ${ }^{[8]}$ This finding does not mirror SA data or even global data. The reason for the high number of deaths from ectopic pregnancies needs to be studied further. This issue may also be related to lateness and nonbooking, as women do not undergo sonography at an early stage to confirm an intra-uterine pregnancy.

The majority of women died after working hours. This may be owing to staff shortages and lack of supervision. In many hospitals, such as Natalspruit Hospital, a consultant is on call every night from 2 weeks to a month. They are not required to be on site, except in the case of an emergency. According to the Royal College of Obstetricians and Gynaecologists, a consultant on call should be available telephonically and when a trainee needs them. Ideally, there should be 24-hour consultant cover in acute obstetric and gynaecology units. A consultant should attend in person to any woman with eclampsia, postpartum haemorrhage $(>1.5 \mathrm{~L})$, a caesarean section for placenta praevia, maternal collapse and a repeat laparotomy. ${ }^{[9]}$ This is not the case in our hospital and many SA hospitals with staff shortages. Maswime and Buchmann ${ }^{[10]}$ described the inequities between regional and district hospitals in Johannesburg, with regional hospitals having 2.7 specialists per 10000 births v. $11.8 / 10000$ births in tertiary hospitals. The MMR in regional hospitals was 204/100 000 compared 
with 136/100 000 in tertiary hospitals. Advocacy for optimal training by universities was considered to be one of the reasons for better staffing and better outcomes in teaching hospitals. ${ }^{[10]}$

\section{Study strengths and limitations}

The strength of this study is that it describes the causes of deaths in a region with a very high MMR, and discusses possible contributors to the high numbers. A more detailed study describing process and structural factors that lead to maternal outcomes would provide more useful data and targeted solutions.

\section{Conclusions}

The MMR is very high at Natalspruit Hospital compared with the national rate. The majority of deaths occurred because of patient-related avoidable factors and during hours when there were few staff on duty.

\section{Declaration. None.}

Acknowledgements. None.

Author contributions. BU: designed the study, collected the data, wrote the manuscript and approved the final draft. SM: designed the study, analysed the data, wrote the manuscript and approved the final draft.
Funding. None.

Conflicts of interest. None.

1. World Health Organization. Global health observatory, maternal mortality. www.who.int/gho/ maternal_health/mortality/maternal_mortality_text/index.html (accessed 26 February 2018).

2. Every Death Counts Writing Group. Every death counts: Use of mortality audit data for decision making to save lives of mothers, babies, and children in South Africa. http://repository.up.ac.za/xmlui/ bitstream/handle/2263/10266/South_Every(2008).pdf?sequence=1 (accessed 26 February 2018).

3. World Health Organization. Maternal mortality. http://www.who.int/mediacentre/factsheets/fs348/ en/ (accessed 26 February 2018).

National Department of Health. Saving Mothers 2011 - 2013: Sixth Report on the Confidentia Enquiries into Maternal Deaths in South Africa. Pretoria: $\mathrm{NDoH}, 2015$.

5. Ikeako L, Ezegwui H, Azuiki E, et al. Maternal deaths in a tertiary health institution in Southeas Nigeria: Two deacades after safe motherhood initiative. JAMMR J Adv Med Med Res 2017;23(9):1-8. https://doi.org/10.9734/JAMMR/2017/35545

6. Stephen DN, Terrumun ZS. Maternal mortality in JOS Nigeria: A facility based prospective review. Int J Biol Med Res 2011;2(2):565-568

7. Pattinson R, Rossouw L. The unbooked mother at Tygerberg Hospital: A prospective controlled study. S Afr Med J 1987;71(9):559-560.

8. Khan K, Wojdyala D, Say L, Gulmezoglu M, van Look P. WHO analysis of causes of maternal death: A systematic review. Lancet 2006;367(9156):1066-1074. https://doi.org/10.1016/S0140-6736(06)68397-9 9. Royal College of Obstetricians and Gynaecologists. Responsibility of consultant on-call. https//www. rcog.org.uk/globalassets/documents/guidelines/goodpractice8responsibilityconsultant.pdf (accessed

10. Maswime S, Buchmann E. Inequities in resources and preparedness for surgical complications of caesarean section in southern Gauteng hospitals. S Afr J Obstet Gynaecol 2016;22(1):22-24. https:// doi.org/10.7196/SAJOG.2016.v2211.1039

Accepted 27 August 2018. 